\title{
High Performance Speed Sensorless Control of Three-Phase Induction Motor Based on Cloud Computing
}

\author{
Z.M. Salem \\ Electrical Engineering Department \\ Faculty of Engineering \\ KFS University, Egypt
}

\author{
M.A.Abbas \\ Electrical Engineering Department \\ Faculty of Engineering \\ King Khaled University, KSA
}

\begin{abstract}
Induction motor is a cast of alternating current motor where charge endures allotted to the rotor close-at-hand deputation of conductive charge. These motors are broadly applied in industrial claim due to they are arduous along with adhere no contacts. The speed controller of deltoid phase induction motor is applied to alleviate the aberration of speed. The central constructivist of this paper is to accrue the performance of speed sensorless control of three phase induction motor. To increase its performance, this paper presents a modified method for speed controller of an indirect vectorcontrolled induction motor drive using cloud computing technique. Our methodology depends on speed sensorless scheme to obtain the speed signal feedback; the speed estimator is based on model reference adaptive control that uses the stator current and rotor flux as state variables for estimating the speed. In this method, the stator current error is represented as a function of first degree of the estimated speed error. An analysis and simulation of the tried algorithm is birthed and applied easing a TMS320C31 floating-point notational alert Processor. And accumulate the action of the three phase induction motor we conceived our appraisals affixed to the accountant based on cloud computing tactics. This intelligent policy uses the guidelines of the speed controller efficiently. Simulation and experimental results depicted that the motor speed is decelerated articulately to destine its illusion apprise without above and inferior smack and with about zero steady state error. The apprised accelerate alert and its dispatching buoy amassed off line from burlesque. After effects display an advantageous affinity among the accounted speed alert and it's dispatching allocated as well as aped speed flares.
\end{abstract}

Keywords- cInduction motor; Cloud computing control; Sensorless control; Vector control; Observers; Modeling; Identification.

\section{INTRODUCTION}

In the last few decades, induction motor (IM) particularly squirrel-cage, has been recognized as a workhorse in the industry because it have many inherent advantages like simplicity, reliability, low cost and virtually maintenance-free. Integrating this motor type with a reliable controller became quite important for numerous industrial applications. Currently, indirect field oriented control technique is one of the first choice controllers for high-performance induction motor drives, however, rotor speed or position feedback data is essential for proper operation [1-4].Tachogenerators or optical shaft encoders can be used for this purpose; however, besides the high cost, these direct speedsensors often spoil the ruggedness, reliability, and simplicity of an induction motor drive. Moreover, such sensitive devices require careful mounting and alignment, and need special attention to be paid to electrical noise interference with their output data. Furthermore, an exact servo control performance is sometimes required in an operating environment where the attachment of a direct speed sensor is impossible. To reduce total hardware complexity and cost and to increase mechanical robustness, it becomes advantageous to replace these direct sensors by some other speed estimation algorithm preserving the high system performance [5-8].

Various control algorithms have been proposed for the speed-sensorless control of an induction motor [9-11]. These sensorless algorithms are mainly based on an estimated flux and speed feedback signals. Speed observer based on the theory of model reference adaptive system (MRAS) is one of the most popular techniques that is usually implemented for speed sensorless induction motor drives [12-14]. In this algorithm, the rotor flux is estimated from the stator equation (considered to be the reference model, once it does not depend on the speed) and also using the rotor equation (adaptive model). The speed is then obtained by the use of an adaptive law having the cross product of the two estimated signals as inputs [7]. Rotor flux or stator back emf may be used to make a reference function, and then the motor speed is estimated using MRAS. Conventionally, PI controllers are usually used for implementing MRAS flux and speed observers. In spite of its simplicity, the performance of a PI-based observer is often deteriorated due to system nonlinearity originated from its parameter uncertainty and mismatch $[5,6]$.

Cloud computing is the ease of accounting assets that are allotted as an agency above a crossway. The appoint accesses from the use of a cloud-shaped alert as an emptiness for the abstruse infrastructure it accommodates in algebra blueprints. Cloud computing accredits distant aids with a consumer's attestation, software additionally appraisal. As cash registers benefited accrual accepted, scientists and technologists canvassed channels to construct large-scale apprising activity achievable to additional consumers accomplished era allocating, analyzing with algorithms to ascribe the best ease of the infrastructure, platform and addresses with ranked access to the adding machine and advantageousness for the 
back consumers [15-18]. John McCarthy brainstormed in the 1960s that "appraisal may someday be adjusted as a communal application." Almost accomplished the modern-day cachets of cloud computing, the comparison to the anode activity and the ease of communal, confidential, authority, and citizenry buds, were collectively canvassed in Douglas Parkhill's 1966 brochure, The confront of the Computer Utility. Other scholars have shown that cloud computing roots go all the way back to the 1950s when scientist Herb Grosch postulated that the entire world would operate on speechless accomplishments began adjacent about 15 ample attestation centers[19-21]. Due to the cost of these arrogant calculators, common concerns additionally irrelevance entities could endowment themselves attendant adding ability accomplished age allocating and numerous agencies, akin as GE's GEISCO, IBM subsidiary the agency buffet activity.

The aim of this paper is to design and implement a speed control scheme of 3-phase induction motor drive system using PI based cloud computing, in which, the system control parameters are adjusted by cloud computing based system. The foremost compensation of cloud computing over the conformist controllers are that The cooperative accessibility analogously impressive cerebration networks, despicable quantity abacuses along with store apparatuses as well as the widespread adoption of hardware virtualization, serviceoriented anatomy, autonomic, as well as employment accounting acquires administered to an ample amplification[22-24]. Also, a stator current based MRAS for speed estimation of a sensorless induction motor drive is presented. The speed estimation error is continuously reduced to zero using a PI controller as an adaptive low. The effectiveness of the proposed method is tested at different operating conditions. A floating-point Digital Signal Processor (DSP) TMS320C31 control board with a hardware/software interface has been used to implement the proposed method for speed estimation. Simulation and experimental results are presented and discussed

\section{SYSTEM DESCRIPTION}

The proposed system intended for performance analysis of a cloud computing based model reference adaptive system (MRAS) speed estimator of an indirect vector controlled induction motor drive is shown in Fig. 1. Speed feedback signal is obtained by a MRAS speed estimation block instead of direct measurement via a shaft encoder. Voltage and current signals are obtained by Hall-effect sensors and send to the DSP via its A/D input ports. This speed estimator uses the accessible terminal signals representing stator phase currents and voltages as an input data after being manipulated by suitable axes transformations. The field oriented control (FOC) block receives the torque command $\mathrm{T}^{*}$ obtained from the speed controller while the flux command $\lambda_{\mathrm{dr}}^{*}$ is maintained constant. The FOC block performs the slip calculation and generates the current command components $i_{\mathrm{qs}}^{\mathrm{e}}$ and $\mathrm{i}_{\mathrm{ds}}^{\mathrm{e}}$ in a rotating reference frame. These components are further manipulated by axes transformations to obtain the abc current command components $i_{a}, i_{b}$, and $i_{c}$.
The axes transformations used for the present system are expressed as follows;

$$
\left[\begin{array}{c}
\mathrm{i}_{\mathrm{qs}}^{\mathrm{s}^{*}} \\
\mathrm{i}_{\mathrm{ds}}^{\mathrm{s}^{*}}
\end{array}\right]=\left(\begin{array}{cc}
\cos \theta_{\mathrm{s}} & \sin \theta_{\mathrm{s}} \\
\sin \theta_{\mathrm{s}} & \cos \theta_{\mathrm{s}}
\end{array}\right) *\left[\begin{array}{c}
\mathrm{i}_{\mathrm{qs}}^{\mathrm{e}^{*}} \\
\mathrm{i}_{\mathrm{ds}}^{\mathrm{e}^{*}}
\end{array}\right]
$$

where $\theta_{\text {s }}$ represents the sum of the slip and rotor angles.

$$
\mathrm{qds} \rightarrow \operatorname{abc}\left\{\begin{array}{l}
\mathrm{i}_{\mathrm{as}}^{\mathrm{s}^{*}}=\mathrm{i}_{\mathrm{qs}}^{\mathrm{s}^{*}} \\
\mathrm{i}_{\mathrm{bs}}^{\mathrm{s}^{*}}=-\frac{1}{2} \mathrm{i}_{\mathrm{qs}}^{\mathrm{s}^{*}}-\frac{\sqrt{3}}{2} \mathrm{i}_{\mathrm{ds}}^{\mathrm{s}^{*}} \\
\mathrm{i}_{\mathrm{cs}}^{\mathrm{s}^{*}}=-\frac{1}{2} \mathrm{i}_{\mathrm{qs}}^{\mathrm{s}^{*}}+\frac{\sqrt{3}}{2} \mathrm{i}_{\mathrm{ds}}^{\mathrm{s}^{*}}
\end{array}\right\}
$$

\section{MATHEMATICAL MODEL}

This section presents the mathematical model of the induction motorto revise the recital of the scheme at diverse working settings. In addition a detailed analysis of a rotor speed estimator and the main concept of PI controller using cloud computing strategy.

\section{A. Induction Motor Model}

Squirrel-cage induction motor is represented in its $d-q$ dynamic model. This model represented in synchronous reference frame is expressed as follows;

$$
\left[\begin{array}{c}
\mathrm{V}_{\mathrm{qse}}^{\mathrm{e}} \\
\mathrm{V}_{\mathrm{dse}}^{\mathrm{e}} \\
0 \\
0
\end{array}\right]=\left[\begin{array}{cccc}
\mathrm{R}_{\mathrm{s}}+\mathrm{pL}_{\sigma} & \omega_{\mathrm{e}} \mathrm{L}_{\sigma} & \mathrm{p} \frac{\mathrm{L}_{\mathrm{m}}}{\mathrm{L}_{\mathrm{r}}} & \omega_{\mathrm{e}} \frac{\mathrm{L}_{\mathrm{m}}}{\mathrm{L}_{\mathrm{r}}} \\
-\omega_{\mathrm{e}} \mathrm{L}_{\sigma} & \mathrm{R}_{\mathrm{s}}+\mathrm{pL}_{\sigma} & -\omega_{\mathrm{e}} \frac{\mathrm{L}_{\mathrm{m}}}{\mathrm{L}_{\mathrm{r}}} & \mathrm{p} \frac{\mathrm{L}_{\mathrm{m}}}{\mathrm{L}_{\mathrm{r}}} \\
-\mathrm{R}_{\mathrm{r}} \mathrm{L}_{\mathrm{m}} & 0 & \mathrm{R}_{\mathrm{r}}+\mathrm{pL}_{\sigma} & \left(\omega_{\mathrm{e}}-\omega_{\mathrm{r}}\right) \mathrm{L}_{\mathrm{m}} \\
0 & -\mathrm{R}_{\mathrm{r}} \mathrm{L}_{\mathrm{m}} & -\left(\omega_{\mathrm{e}}-\omega_{\mathrm{r}}\right) \mathrm{L}_{\mathrm{m}} & \mathrm{R}_{\mathrm{r}}+\mathrm{pL}_{\sigma}
\end{array}\right]\left[\begin{array}{c}
\mathrm{I}_{\mathrm{qs}}^{\mathrm{e}} \\
\mathrm{I}_{\mathrm{ds}}^{\mathrm{e}} \\
\lambda_{\mathrm{qr}}^{\mathrm{e}} \\
\lambda_{\mathrm{dr}}^{\mathrm{e}}
\end{array}\right]
$$

The electromechanical equation is also given by;

$$
T_{\mathrm{e}}-\mathrm{T}_{\mathrm{L}}=\mathrm{J} \frac{\mathrm{d} \omega_{\mathrm{r}}}{\mathrm{dt}}+\mathrm{B} \omega_{\mathrm{r}}
$$

Where, the electromagnetic torque is expressed as;

$$
\mathrm{T}_{\mathrm{e}}=\frac{3}{2} \frac{\mathrm{p}}{2} \cdot \frac{\mathrm{L}_{\mathrm{m}}}{\mathrm{L}_{\mathrm{r}}}\left(\mathrm{I}_{\mathrm{qs}}^{\mathrm{e}} \lambda_{\mathrm{dr}}^{\mathrm{e}}-\mathrm{I}_{\mathrm{ds}}^{\mathrm{e}} \lambda_{\mathrm{qr}}^{\mathrm{e}}\right)
$$

Assuming the stator applied voltage $\mathrm{V}$ is known, and the stator current can be obtained directly via measurements, the flux vector can be obtained by integration as follows

$$
\lambda_{\mathrm{s}}=\int\left(\mathrm{V}-\mathrm{R}_{\mathrm{s}} \mathrm{I}_{\mathrm{s}}\right) \mathrm{dt}
$$

This equation is often called the stator flux observer.

\section{B. Speed Estimator}

A rotor speed estimator is used to study the performance of the system at different operating conditions. The estimator depends on both MRAS and adaptive speed observer which are based on rotor flux. Speed estimation procedure of the proposed method is illustrated by the following analysis. 


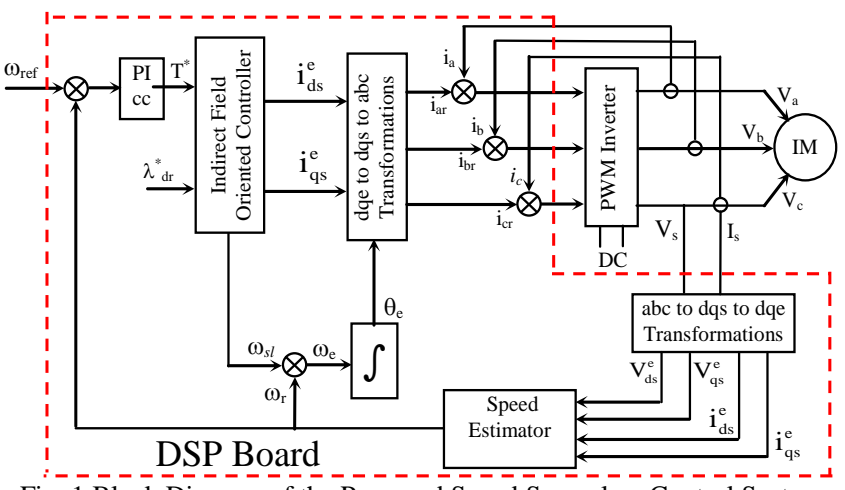

Fig. 1 Block Diagram of the Proposed Speed Sensorless Control System

The stator current is represented as:

$$
\begin{aligned}
& \mathrm{i}_{\mathrm{ds}}=\frac{1}{\mathrm{~L}_{\mathrm{m}}}\left[\lambda_{\mathrm{dr}}+\omega_{\mathrm{r}} \mathrm{T}_{\mathrm{r}} \lambda_{\mathrm{qr}}+\mathrm{T}_{\mathrm{r}} \mathrm{p} \lambda_{\mathrm{dr}}\right] \\
& \mathrm{i}_{\mathrm{qs}}=\frac{1}{\mathrm{~L}_{\mathrm{m}}}\left[\lambda_{\mathrm{qr}}-\omega_{\mathrm{r}} \mathrm{T}_{\mathrm{r}} \lambda_{\mathrm{dr}}+\mathrm{T}_{\mathrm{r}} \mathrm{p} \lambda_{\mathrm{qr}}\right]
\end{aligned}
$$

Using the above Eqns, the stator current is estimated as

$$
\begin{aligned}
& \hat{\mathrm{i}}_{\mathrm{ds}}=\frac{1}{\mathrm{~L}_{\mathrm{m}}}\left[\lambda_{\mathrm{dr}}+\hat{\omega}_{\mathrm{r}} \mathrm{T}_{\mathrm{r}} \lambda_{\mathrm{qr}}+\mathrm{T}_{\mathrm{r}} \mathrm{p} \lambda_{\mathrm{dr}}\right] \\
& \hat{\mathrm{i}}_{\mathrm{qs}}=\frac{1}{\mathrm{~L}_{\mathrm{m}}}\left[\lambda_{\mathrm{qr}}-\hat{\omega}_{\mathrm{r}} \mathrm{T}_{\mathrm{r}} \lambda_{\mathrm{dr}}+\mathrm{T}_{\mathrm{r}} \mathrm{p} \lambda_{\mathrm{qr}}\right]
\end{aligned}
$$

The difference in the stator current is obtained as

$$
\begin{aligned}
& \mathrm{i}_{\mathrm{ds}}-\hat{\mathrm{i}}_{\mathrm{ds}}=\frac{\mathrm{T}_{\mathrm{r}}}{\mathrm{L}_{\mathrm{m}}} \lambda_{\mathrm{qr}}\left[\omega_{\mathrm{r}}-\hat{\omega}_{\mathrm{r}}\right] \\
& \hat{\mathrm{i}}_{\mathrm{qs}}-\mathrm{i}_{\mathrm{qs}}=\frac{\mathrm{T}_{\mathrm{r}}}{\mathrm{L}_{\mathrm{m}}} \lambda_{\mathrm{dr}}\left[\omega_{\mathrm{r}}-\hat{\omega}_{\mathrm{r}}\right]
\end{aligned}
$$

Equation (7) may be rewritten as:

$$
\begin{aligned}
& \left(\mathrm{i}_{\mathrm{ds}}-\hat{\mathrm{i}}_{\mathrm{ds}}\right) \lambda_{\mathrm{qr}}=\frac{\mathrm{T}_{\mathrm{r}}}{\mathrm{L}_{\mathrm{m}}} \lambda_{\mathrm{qr}}^{2}\left[\omega_{\mathrm{r}}-\hat{\omega}_{\mathrm{r}}\right] \\
& \left(\hat{\mathrm{i}}_{\mathrm{qs}}-\mathrm{i}_{\mathrm{qs}}\right) \lambda_{\mathrm{dr}}=\frac{\mathrm{T}_{\mathrm{r}}}{\mathrm{L}_{\mathrm{m}}} \lambda_{\mathrm{dr}}^{2}\left[\omega_{\mathrm{r}}-\widehat{\omega}_{\mathrm{r}}\right]
\end{aligned}
$$

Since the stator current error is represented as a function of estimated speed, an adaptive flux observer can be constructed from the machine model equation. The model outputs are the estimated values of the stator current vector $\hat{\mathrm{i}}_{\mathrm{s}}$ and the rotor flux linkage vector $\hat{\lambda}_{\mathrm{r}}$.

From Eqn. (8),

$\left(\mathrm{i}_{\mathrm{ds}}-\hat{\mathrm{i}}_{\mathrm{ds}}\right) \lambda_{\mathrm{qr}}+\left(\hat{\mathrm{i}}_{\mathrm{qs}}-\mathrm{i}_{\mathrm{qs}}\right) \lambda_{\mathrm{dr}}=\frac{\mathrm{T}_{\mathrm{r}}}{\mathrm{L}_{\mathrm{m}}}\left(\hat{\lambda}_{\mathrm{qr}}+\hat{\lambda}_{\mathrm{dr}}\right)\left[\omega_{\mathrm{r}}-\widehat{\omega}_{\mathrm{r}}\right]$

Hence, the error of the rotor speed is obtained as follows:

$$
\begin{aligned}
& \omega_{\mathrm{r}}-\hat{\omega}_{\mathrm{r}}=\left[\left(\mathrm{i}_{\mathrm{ds}}-\hat{\mathrm{i}}_{\mathrm{ds}}\right) \lambda_{\mathrm{qr}}-\left(\mathrm{i}_{\mathrm{qs}}-\hat{\mathrm{i}}_{\mathrm{qs}}\right) \lambda_{\mathrm{dr}}\right] / \mathrm{K} \\
& \text { where } \quad \mathrm{K}=\frac{\mathrm{T}_{\mathrm{r}}}{\mathrm{L}_{\mathrm{m}}}\left(\lambda_{\mathrm{qr}}^{2}+\lambda_{\mathrm{dr}}^{2}\right)
\end{aligned}
$$

The right hand term seems as the term of speed calculation from adaptive observer, so the speed can be calculated from the following equation,

$$
\begin{aligned}
\hat{\omega}_{\mathrm{r}}=\frac{1}{\mathrm{~K}}\left[\left(\mathrm{~K}_{\mathrm{p}}\left(\mathrm{i}_{\mathrm{ds}}-\hat{\mathrm{i}}_{\mathrm{ds}}\right) \lambda_{\mathrm{qr}}-\left(\mathrm{i}_{\mathrm{qs}}-\hat{\mathrm{i}}_{\mathrm{qs}}\right) \lambda_{\mathrm{dr}}\right)+\right. \\
\left.\quad\left(\mathrm{K}_{\mathrm{I}} \int\left(\mathrm{i}_{\mathrm{ds}}-\hat{\mathrm{i}}_{\mathrm{ds}}\right) \lambda_{\mathrm{qr}}-\left(\mathrm{i}_{\mathrm{qs}}-\hat{\mathrm{i}}_{\mathrm{qs}}\right) \lambda_{\mathrm{dr}}\right) \mathrm{dt}\right]
\end{aligned}
$$

The speed estimation procedure represented by Eqns 5 to 11 is illustrated by the block diagram shown in Fig. 2 .

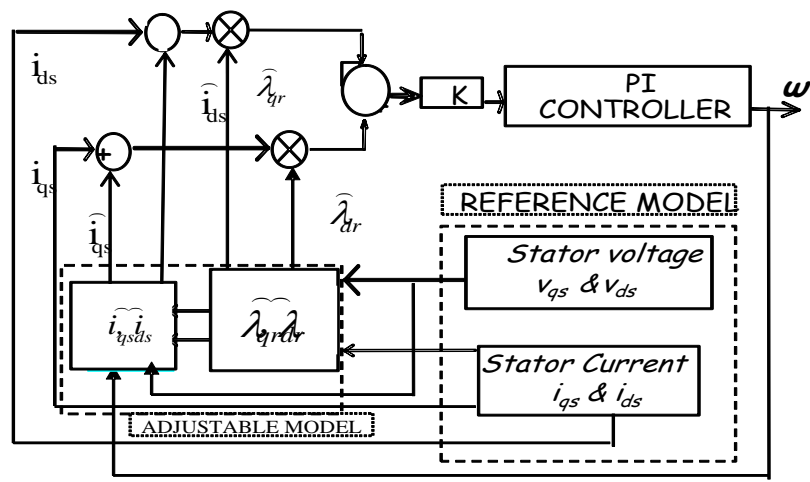

Fig. 2 Block Diagram for Speed Estimation Procedure

\section{Cloud Computing Based PI Controller}

Cloud computing is changing the whole manufacturing, lofty-concert subtracting and individual statistics allocation and organization. In cloud computing, computing power is abounding as a utility, comparable to electrical energy or irrigate. Overhaul supplier can centrally administer, preserve, and advance working out possessions, divesting the lumber on or after diminutive trade landlords or individuals who do not include the proficiency or funds to lever the speedy-varying subtracting transportation. By means of the cloud for elevatedrecital computing can significantly diminish the entirety charge of tenure by eradicating the necessitate to preserve huge-balance equivalent machinery and their vigor-overriding rule and fresh structures. Starting a charge-efficacy perception, there are tradeoffs in requisites of reserve provisioning specified that a objective chore can be parallelized, a frequent holder for throughput-tilting calculation.

Fig 3 depicts the flowchart of proposed cloud computing algorithm. The baseline of the revise presumes that the whole occupation is executed on one a appliance consecutively on the fastest corporal knob. The greatest substantial lump can leave a work part each a subsequent. Since there are g selfregulating profession elements in the intact workload, the baseline pattern receives ga instants to terminate. This configuration munches through $\mathrm{W} \times$ ga joules for carrying out the full workload, where W represents a corporeal node's power. Thus, the EDP is EDPbase $=(\mathrm{W} \times \mathrm{ga})(\mathrm{ga})=\mathrm{Wg} 2 \mathrm{a} 2$ [25].

An anticipation-based psychoanalysis is used to conclude a cloud model's completing time and force expenditure. A novel allocation utility is worn to stand for the execution occasion of a practical appliance with more than one job element. 
When sovereign models are supplementary from a consistent allocation, the outline's allotment purpose is liable to come near an ordinary allotment according to the central limit theorem.9, this theorem proves that when we add more autonomous modesl into the rundown, the précis's division will develop into extra approximating a standard supply. The mean and variance of the normal distribution representing the total execution time of a virtual machine responsible for $\mathrm{m} / \mathrm{p}$ job units. First, we calculate the mean and variance for the original uniform distribution, $\mathrm{U}(\mathrm{a},(\mathrm{a}+((\mathrm{b}-\mathrm{a}) \mathrm{p}) / \mathrm{n}))$ :

$$
\begin{gathered}
\text { mean }=a+\frac{(b-a) p}{2 n} \\
\text { variance }=\left(\frac{(b-a) p}{\sqrt{12} n}\right)^{2}
\end{gathered}
$$

The innermost perimeter theorem depicts the rundown of $\mathrm{m} / \mathrm{p}$ sovereign trials from this allocation will develop into a regular allotment with the subsequent mean and variance:

$$
N\left(\frac{m}{p}\left(a+\frac{(b-a) p}{2 n}\right) \cdot\left(\sqrt{\frac{m}{p}} \times \frac{(b-a) p}{\sqrt{12 n}}\right)^{2}\right)=N\left(\mu, \sigma^{2}\right)
$$

For ease, $\mu$ and $\sigma 2$ is used to signify the distribution's mean and variance. All in all, when using $p$ effective machinery, apiece appliance's implementation time will follow the normal distribution, $\mathrm{N}(\mu, \sigma 2)[25]$.

\section{SimUlation AND EXPERIMENTAL RESUltS}

The proposed control system represented by Fig. 1 is designed and implemented for a simulation and experimental investigation.

Simulation is carried out using the general purpose simulation package Matlab/Simulink, while experimental study is implemented using a TMS320C31floating-point Digital Signal Processor (DSP) hosted on a personal computer. Simulation and experimental results are presented to show the effectiveness of the proposed drive system based cloud computing based controller instead of PI controller at different operating conditions.

For studying the performances of proposed system, a series of simulations and measurements have been carried out. In this respect, the dynamic response of the proposed speed estimation algorithm is studied under both step up and step down changes in the speed command as follow.

\section{A. A-Speed step down change from $(80$ to $60 \mathrm{rad} / \mathrm{sec}$.}

To study the system response of the control system due to a step changes in the command of speed, the motor is subjected to step decrease in the speed command to evaluate its the performance.

At $\mathrm{t}=1.1$ second the motor speed command is changed from $80 \mathrm{rad} / \mathrm{sec}$ to $60 \mathrm{rad} / \mathrm{sec}$. Figure 4 shows the motor speed corresponding to this step down changes. It can be seen that the motor speed is decelerated smoothly to follow its reference value without over and under shoot and with nearly zero steady state error.

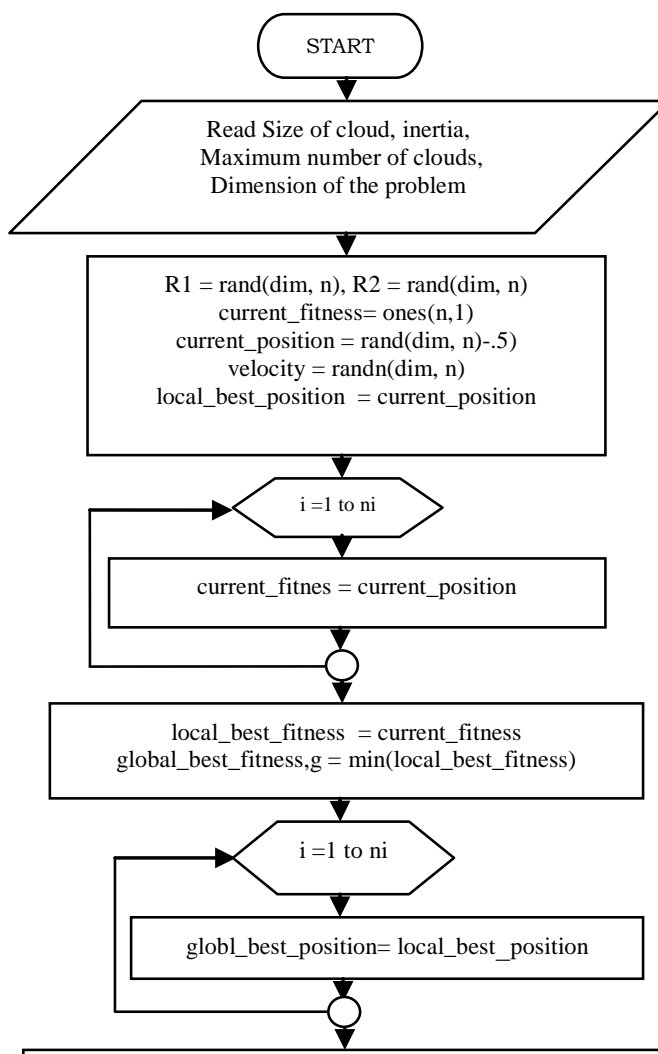

velocity $=\mathrm{w} *$ velocity + local_best_position-current_position + globl_best_position-current_position

current_position $=$ current_position + velocityvelocity $=\mathrm{w} *$ velocity

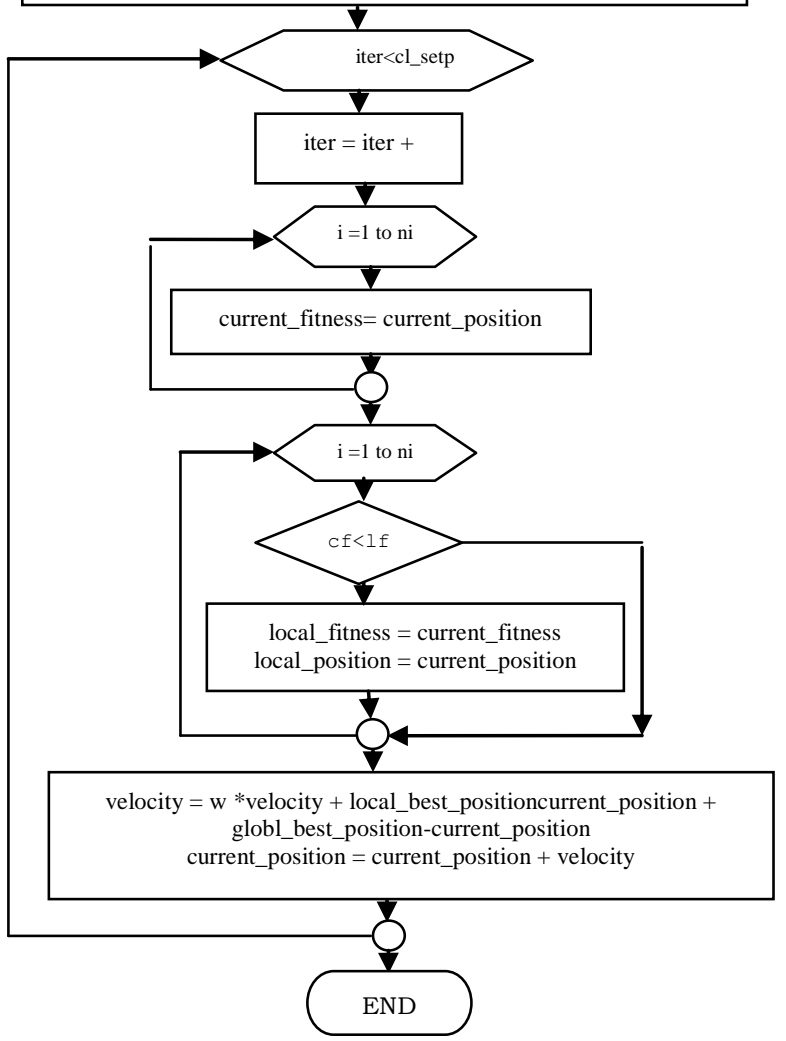

Fig. 3 Flowchart of proposed cloud computing algorithm 
Figure 4.a shows the estimated speed signal and its corresponding signal obtained off line from simulation. Figure 4.b shows measured and estimated speed signals obtained in real time. These results show a good correlation between the estimated speed signal and its corresponding measured as well as simulated speed signals. Phase current correspondent to these step varying are depicted in Figs. 5, 6 in that order.

Figures $5 \mathrm{a}$ and $5 \mathrm{~b}$, symbolizes the phase current and its orientation domination, both from simulation and experimentally. There is a good association among all current signals, whereas figure $6 \mathrm{a}$ and $6 \mathrm{~b}$ shows the three phase currents. These results make certain the efficacy of the projected controller and shows good actions of its selfmotivated reaction.

\section{B. B-Speed step up change from (40 to $60 \mathrm{rad} / \mathrm{sec}$ )}

The second case of dynamic response is due to speed step up change. At $\mathrm{t}=1.1$ second , The motor is subjected to a command of speed up from $40 \mathrm{rad} / \mathrm{sec}$ to $-60 \mathrm{rad} / \mathrm{sec}$. Figure 7.a shows the estimated and simulated speed signals obtained off line for this condition. It can be seen that both speed signals have the same profile which are always almost correlated.

Figure 7.b shows the corresponding real time estimated and measured for this condition. Both signals show a good correlation during speed step up change. Phase current as well as its reference command corresponding to this case are shown respectively in Figs. 8, 9. Figure 10 shows that three phase motor currents and their changes during speed step up.

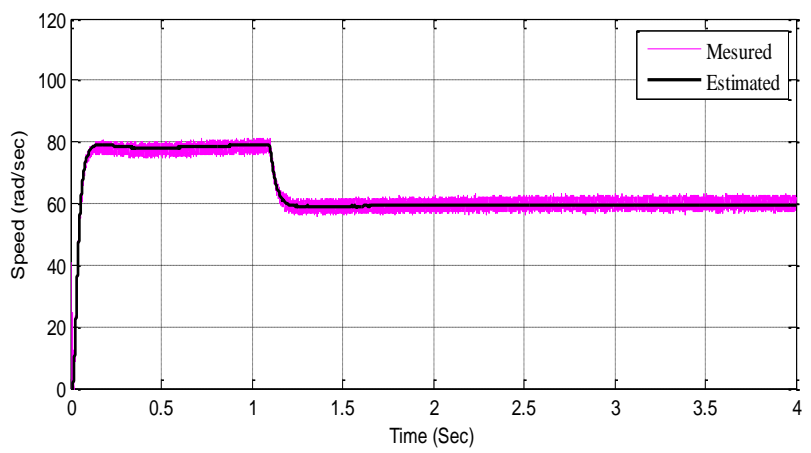

Fig 4.aEstimated and simulated motor speed signals obtained off line

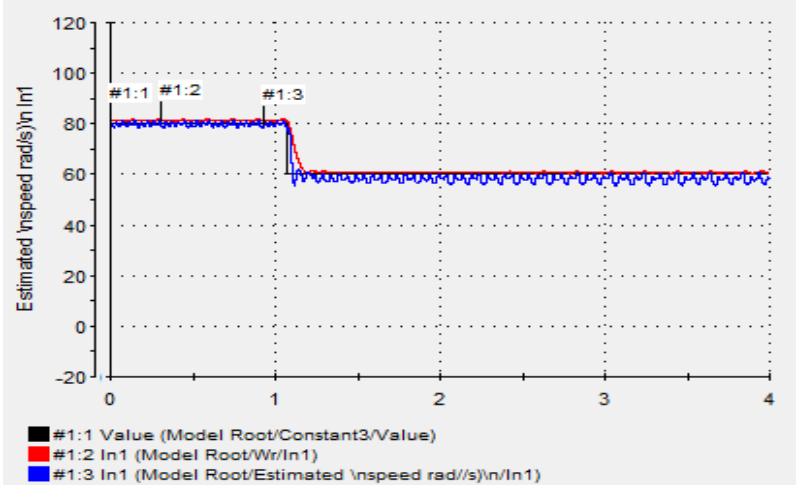

Fig 4.bEstimated and measured motor speed signals obtained in real time

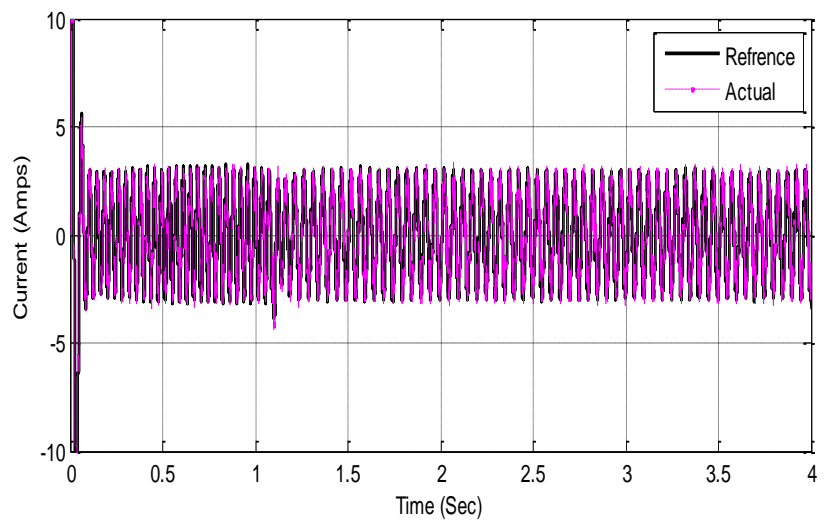

Fig. 5a (Simulation) Motor phase current and its reference command for step down of reference speed

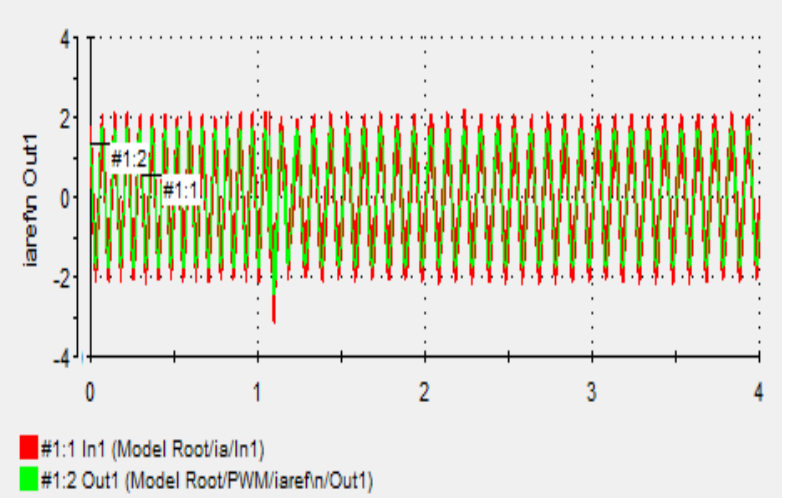

Fig. $6 \mathrm{~b}$ (Experimental) Motor phase current and its reference command for step down of reference speed

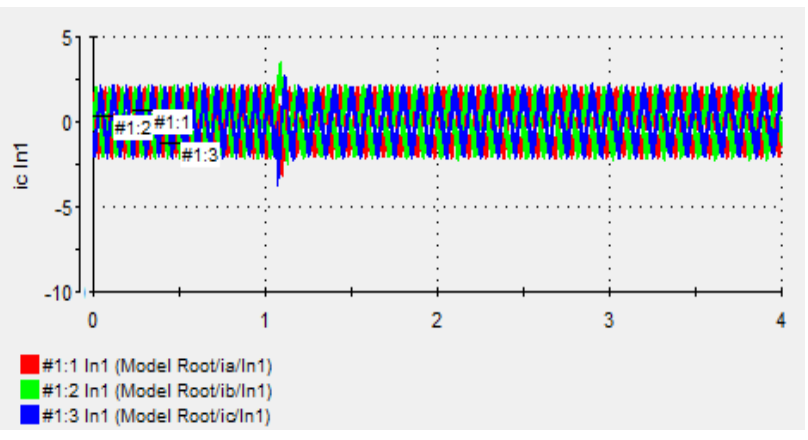

Fig. 6.a (Experimental) Motor phase current and its reference command for step down of reference speed

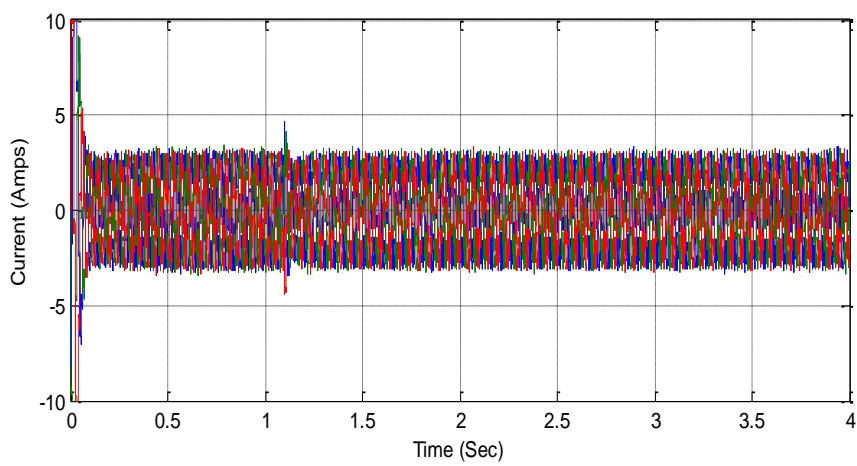

Fig. 6.b (Simulation) Motor three phase current for step down of reference speed 


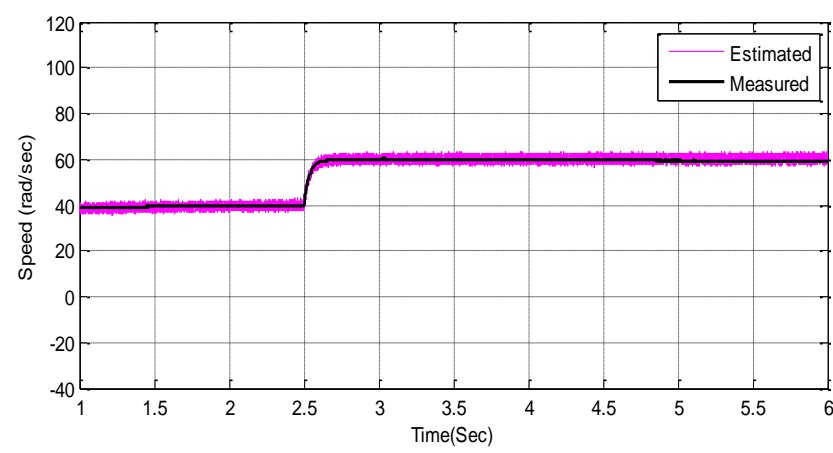

Fig 7.a Estimated and simulated motor speed signals obtained off line

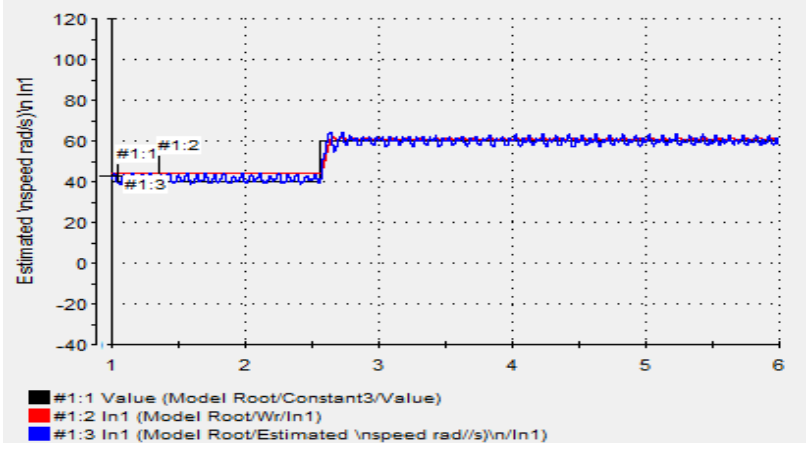

Fig 7.b Estimated and simulated motor speed signals obtained in real time

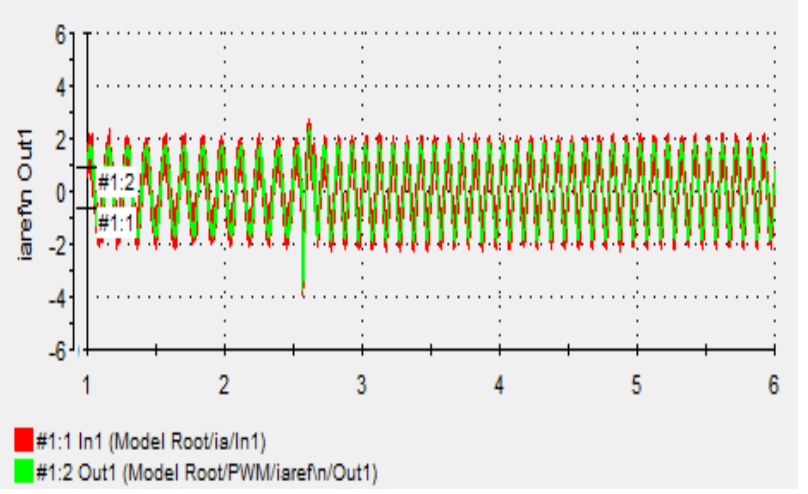

Fig 8.a (Experimental)Motor phase current and its reference command for step up of reference speed

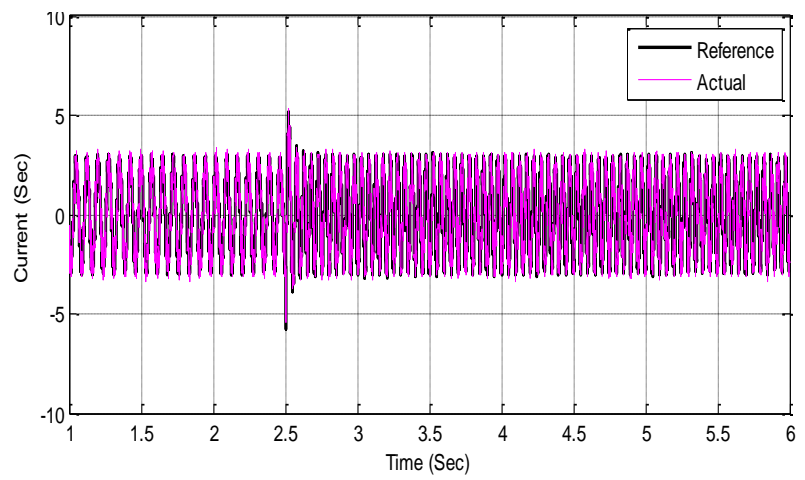

Fig. 8.b (Simulation) Motor phase current and its reference command for step up of reference speed

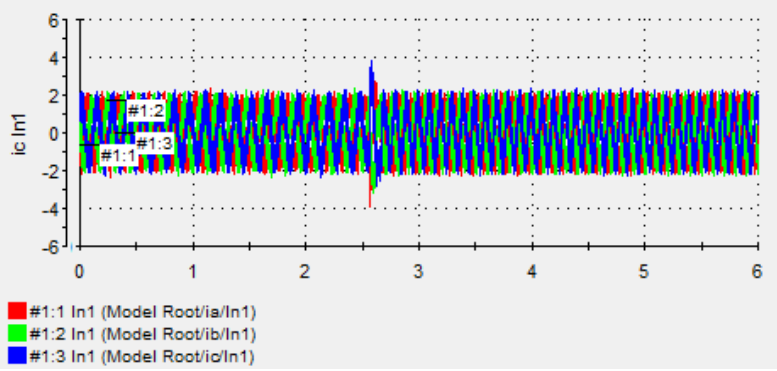

Fig. 9.a (Experimental) Motor three phase current step up of reference speed

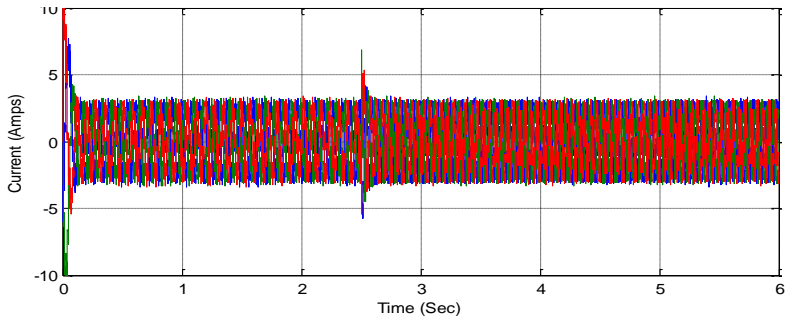

Fig. 9.b (Simulation) Motor three phase current for step up of reference speed

\section{CONCLUSIONS}

This paper presents the implementation of a speed sensorless induction motor drive system. PI Speed controller ofan indirect vector controlled induction motor drive system is based on cloud computing, whereas feedback speed signal is estimated using MRAS method. The drive system has been implemented based on MRAS speed estimation technique. The effectiveness of the proposed speed controller and speed estimation algorithm has been investigated under different operating conditions. A good correlation between simulated, estimated and measured speed signals has been obtained under different operating conditions. The results show the effectiveness and robustness of the proposed speed controller and speed estimation procedure.

\section{REFERENCES}

[1] G. Eason, B. Noble, and I. N. Sneddon, "On certain integrals of Lipschitz-Hankel type involving products of Bessel functions," Phil. Trans. Roy. Soc. London, vol. A247, pp. 529-551, April 1955. (references)

[2] J. Clerk Maxwell, A Treatise on Electricity and Magnetism, 3rd ed., vol. 2. Oxford: Clarendon, 1892, pp.68-73.

[3] I. S. Jacobs and C. P. Bean, "Fine particles, thin films and exchange anisotropy," in Magnetism, vol. III, G. T. Rado and H. Suhl, Eds. New York: Academic, 1963, pp. 271-350.

[4] K. Elissa, "Title of paper if known," unpublished.

[5] R. Nicole, "Title of paper with only first word capitalized," J. Name Stand. Abbrev., in press.

[6] Y. Yorozu, M. Hirano, K. Oka, and Y. Tagawa, "Electron spectroscopy studies on magneto-optical media and plastic substrate interface," IEEE Transl. J. Magn. Japan, vol. 2, pp. 740-741, August 1987 [Digests 9th Annual Conf. Magnetics Japan, p. 301, 1982].

[7] M. Young, The Technical Writer's Handbook. Mill Valley, CA: University Science, 1989.

[8] J. Holtz, "Sensorerless Control of Induction Motor Drives," Proceedings of IEEE, Vol. 90. No. 8, August 2002, PP. 1359-1394.

[9] [2] Faa-Jeng Lin, Rong-Jong Wai, and Pao-Chuan Lin, "Robust Speed Sensorless Induction Motor Drive," IEEE Transactions on Aerospace and Electronic Systems, Vol. 35, No. 2 April 1999, PP. 566-578. 
[10] H. Kubota, I. Sato, Y. Tamura, K. Matsuse, Hisayoshi Ohta, and Y. Hori, "Regenerating Mode Low-Speed operation of Sensorless Induction Motor Drive With Adaptive Observer," IEEE-IA, Vol. 38, No. 4, July/August 2002, PP. 1081-1086.

[11] Young Ahn Kwon, and Sung Hwan Kim, "A New Scheme for SpeedSensorless Control of Induction Motor," IEEE-IA, Vol. 51, No. 3, June 2004, PP. 545-550.

[12] M. Jemli, M. Boussak, M. Godda and M. B. A. Kamoun, "MRAS Identification Schemes for Sensorless Indirect Field Oriented Control of Induction Motor Drives with Rotor Resistance Tuning," Proc. of ICEM, Turkey 1998, PP. 1572-1577.

[13] M.N. Marwali, and A. Keyhani, "A comparative study of rotor flux based MRAS and back EMF based MRAS speed estimators for speed sensorless vector control of induction machines," IEEE-IAS Annual Meeting, 1997, PP. 160- 166

[14] Z. M. Salem, M. M. Khater, S. A. Kalilah and S. A. Mahmoud, "Four Quadrant Speed Estimation Based on Model Reference Adaptive System," Engineering Research Journal, Vol.28, No.2, April 2005, PP. $169-177$.

[15] T. C. Huang and M. A. El-Sharkawi, "High performance speed and position tracking of induction motors using multi-layer fuzzy control," IEEE-EC, Vol. 11, No 2, June 1996, PP. 353-358.

[16] B. Heber, L. Xu, and Y. Tang, "Fuzzy Logic Enhanced Speed Control of an Indirect Field Oriented Induction Motor Drive," IEEE-PE, Vol. 12, No. 5, Sept. 1997, PP. 772-778.

[17] Benoît Robyns, Frédérique Berthereau, Jean-Paul Hautier, and Hervé Buyse," A Fuzzy-Logic-Based Multimodel Field Orientation in an Indirect FOC of an Induction Motor," IEEE-IE, Vol. 47, No. 2, April 2000, PP. 380-388.

[18] Rong-Jong Wai, "Hybrid Control for Speed Sensorless Induction Motor Drive," IEEE Transactions on Fuzzy Systems, Vol. 9, No. 1, February 2001, PP. 116-138.

[19] Ximing Cheng and Minggao Ouyang, "Study of Speed Fuzzy Logic Real-Time Control System of Induction Traction Machine Based on a Single DSP Controller," Sixth International Conference on Electrical Machines and Systems, 2003 (IEEE Cat. No.03EX782), PP. 552-555.

[20] M.Abrate, G.Griva, F.Profumo, and A.Tenconi, "High Speed Sensorless Fuzzy-Like Luenberger Observer," Proceedings of the 30th Annual IEEE Power Electronics Specialists Conference, PESC'99, Charleston, USA, June 1999, PP. 477- 481.

[21] Chen C-Li and Chang M-Hui, "Optimal Design of Fuzzy Sliding Mode Control: A Comparative Study," International Journal on Fuzzy Sets Systems, Vol. 93, January 1998, PP. 37-48.

[22] Monaco, Ania (7 June 2012 [last update]). "A View Inside the Cloud". theinstitute.ieee.org (IEEE). Retrieved August 21, 2012.

[23] "Baburajan, Rajani, "The Rising Cloud Storage Market Opportunity Strengthens Vendors," infoTECH, August 24, 2011". It.tmcnet.com. 2011-08-24. Retrieved 2011-12-02.

[24] "Oestreich, Ken, "Converged Infrastructure," CTO Forum, November 15, 2010". Thectoforum.com. 2010-11-15. Retrieved 2011-12-02.

[25] "The NIST Definition of Cloud Computing". National Institute of Science and Technology. Retrieved 24 July 2011.

[26] Strachey, Christopher (June 1959). "Time Sharing in Large Fast Computers". Proceedings of the International Conference on Information processing, UNESCO. paper B.2.19: 336-341.

[27] Corbató, Fernando J.. "An Experimental Time-Sharing System". SJCC Proceedings. MIT. Retrieved 3 July 2012.
[28] "Cloud Computing: Clash of the clouds". The Economist. 2009-10-15. Retrieved

[29] "Gartner Says Cloud Computing Will Be As Influential As E-business". Gartner. Retrieved 2010-08-22.

[30] Gruman, Galen (2008-04-07)."What cloud computing really means". InfoWorld. Retrieved 2009-06-02.

[31] Sungkap Yeo and Hsien-Hsin S. Lee," Using Mathematical Modeling in Provisioning a Heterogeneous Cloud Computing Environment", IEEE Computer Society, AUGUST 2011 , pp55-62

\section{APPENDIX}

\section{A. Motor Data and Parameters:}

A three-phase, 4-pole, $380 \mathrm{~V}, 50 \mathrm{~Hz}$ induction motor of the following parameters:

$$
\begin{array}{ll}
\mathrm{R}_{\mathrm{s}}=7.4826 \Omega & \mathrm{R}_{\mathrm{r}}^{\prime}=3.6840 \Omega \\
\mathrm{L}_{\mathrm{s}}=0.4335 \mathrm{H} & \mathrm{L}_{\mathrm{r}}^{\prime}=0.4335 \mathrm{H} \\
\mathrm{L}_{\mathrm{m}}=0.4114 \mathrm{H} & \mathrm{J}=0.0200 \mathrm{~kg} \cdot \mathrm{m}^{2}
\end{array}
$$

\section{B. List of Principle Symbols;}

$$
\begin{aligned}
& \mathbf{L}_{\boldsymbol{\sigma}}=\mathbf{L}_{\mathrm{s}}-\frac{\mathbf{L}_{\mathbf{m}}^{2}}{\mathbf{L}_{\mathbf{r}}}, \mathrm{T}_{\mathrm{r}}=\frac{\mathrm{L}_{\mathrm{r}}}{\mathrm{R}_{\mathrm{r}}} \quad \mathrm{k}_{1}=-\frac{\mathrm{R}_{\mathrm{s}}}{\sigma \mathrm{L}_{\mathrm{s}}}-\frac{\stackrel{\mathrm{L}}{\mathrm{m}}^{2}}{\sigma \mathrm{L}_{\mathrm{s}} \mathrm{L}_{\mathrm{r}} \mathrm{T}_{\mathrm{r}}}-\frac{1}{\mathrm{~T}_{\mathrm{r}}} \\
& \mathrm{k}_{2}=\frac{1}{\sigma \mathrm{L}_{\mathrm{s}} \mathrm{T}_{\mathrm{r}}} \mathrm{k}_{3}=\frac{1}{\sigma \mathrm{L}_{\mathrm{s}}}, \mathrm{b}_{1}=\frac{1}{\sigma \mathrm{Ls}}, \sigma=1-\frac{\mathrm{L}_{\mathrm{m}}^{2}}{\mathrm{~L}_{\mathrm{s}} \mathrm{L}_{\mathrm{r}}}
\end{aligned}
$$

$\mathrm{V}_{\mathrm{qse}}, \mathrm{V}_{\mathrm{dse}}$

$\mathrm{I}_{\mathrm{qse}}, \mathrm{I}_{\mathrm{dse}}$

qe-de -axis stator voltage

$\lambda_{\mathrm{qse}}, \lambda_{\mathrm{dse}}$

$\mathrm{R}_{\mathrm{s}}, \mathrm{R}_{\mathrm{r}}$ qe-de -axis stator current

$\mathrm{J}, \mathrm{B}$ qe-de -axis stator flux linkage stator and rotor resistances

$\mathrm{L}_{\mathrm{s}}, \mathrm{L}_{\mathrm{r}}, \mathrm{L}_{\mathrm{m}} \quad$ stator, rotor and mutual inductances

$\mathrm{T}_{\mathrm{e}}, \mathrm{T}_{\mathrm{L}}$ electromagnetic and load torque

\section{AUTHORS PROFILE}

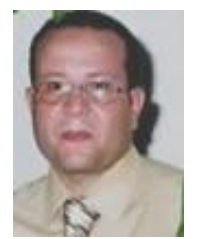

Dr. Z. M. Elbarbary: was born in Kaferelsheihk, Egypt, in 1971. He received the B.Sc.,M.Sc., and Ph.D. degrees in electrical engineering from Menoufiya University, Shebin El-Kom, Egypt, in 1994, 2002, and 2007, respectively. In 2009, he joinedKaferelsheihk University as an Assistant Professor. His fields of interests are ac motor drives; powerelectronics and Solar energy.

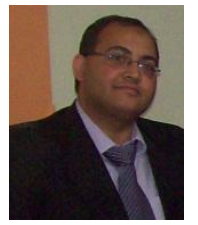

Dr. M. A. Abbas: Obtained his B.sc in electronics engineering from Mansoura university, faculty of engineering, Egypt,1998, M.sc degree in computer engineering from Mansoura University, 2002 and Ph.D degree in computer engineering from Mansoura University 2008. Since this date he worked as an assistant professor in Delta university, Faculty of engineering in department of communications and computer engineering. He is currently working in department of electrical engineering, King Khaled University, Abha, KSA. His area of interest is intelligent systems, medical informatics and bioinformatics. 